\title{
Explosion risk assessment model for underground mine atmosphere
}

\author{
Jianwei Cheng ${ }^{\mathrm{a}, \mathrm{b}, \mathrm{c}^{*}}$, Ziming Bai ${ }^{\mathrm{a}}$, Apurna Ghosh ${ }^{\mathrm{b}}$ \\ ${ }^{a}$ Key Laboratory of Gas and Fire Control for Coal Mines, College of safety engineering, China University of Mining and \\ Technology,Xuzhou,Jiangsu,221116, China \\ ${ }^{b}$ Department of Mining Engineering and Metallurgical Engineering, Western Australian School of Mines, Curtin \\ University, Kalgoorlie, WA 6430, Australia \\ ${ }^{c}$ Department of Mining Engineering, West Virginia University, Morgantwon, WV 26506, USA
}

\begin{abstract}
In coal mining industry, explosions or mine fires present the safety threats for coal miners or mine rescues members. Hence, the determination of the explosibility is critical for mine rescues or controlling the severity of a mine accident, especially for a gas explosion event. However, most current methods although can identify the explosibility, but it lacks in identifying the risk trend. On the other hand, the composition in an underground sealed atmosphere is complicated and also is dynamically changed due to various external or internal influence factors. Although knowing the atmospheric status is always a tedious problem for mining engineers, related analyzing methods are still urgently desired. In order to improve the mine safety, this paper is going to address the abovementioned problems. Based on the characteristics of the Coward explosibility diagram, several quantitative mathematical analyzing models are proposed to address following problems: 1) for a "not-explosive" atmosphere, judging the trend of explosion risk and estimating the state changing time span from
\end{abstract}

\footnotetext{
* Corresponding author. Jianwei Cheng. Tel.: +86-516-8359-0598

E-mail address: jchengwvu@gmail.com

1
} 
"not-explosive" to "explosive"; 2) for an "explosive" atmosphere, estimating the "critical" time span of moving out of explosive state and putting forward mitigation strategy. Such research efforts will not only help the mine operators understand the explosibility risk of a sealed mine atmosphere, but also provide a useful tool to wisely control such atmosphere away from . In order to demonstrate the research findings, case demonstrations for derived models are also shown and can be used to instruct readers how to apply them. The results provide useful information for effectively controlling an explosive underground sealed atmosphere.

Keywords: Mine atmosphere, Explosibility, Coward diagram, Mitigations

\section{Introduction}

Explosions originated from or around the sealed off areas in underground coal mines present a serious safety threat. Statistical data from China in the year of 2009 show that a total of 157 gas explosions were responsible for 755 fatalities in Chinese coal mines (Huang, 2010). Therefore, management of mine atmosphere is an important task for mining engineers.

The explosibility of gas depends on the flammability limits, which has been recognized for more than two centuries. Until now, a great amount of research has been done (Ishizuka, 1991; Britton, 2002; Ma, 2011; Ma, 2013; Ma and Larrañaga, 2015; Mashuga and Crowl, 2000), which provides the fundamentals of explosion risk analysis. Moreover, for application reasons, a number of flammability diagrams has also been developed to take advantages of presenting data figuratively (Timko and Derick, 2006; Cheng et al., 2012; Jacobs and Porter, 1998; Kukuczka, 1982; 
Ray et al., 2004), so that are useful for dealing with multiple species in a flammable mixture. However, all the graphical methods could only provide the judgement as "explosive" or "notexplosive", which cannot really define the safety margin of a gas atmosphere. How to accurately determine such measures' effect time is still a question. It needs to be answered for a mining engineer or mine rescue worker. In consideration of the mine atmosphere, its explosibility highly depends on the composition of oxygen, combustible and inert gases. It should be noted that the composition in the inaccessible sealed areas change with time under the influences of inflows of combustible gases, air leakage, inert gases injected, etc., which also brings the difficulties to make any explosion risk estimations. In order to improve the mine safety and assist the mine accident mitigation strategies, this paper is going to introduce a series of graphical method based models to address the above problems. The major advantages /contributions of these models are:

a) For a "not-explosive" mine atmosphere, quantitative analysis could be made to optimize the explosion risk mitigation strategies.

b) Accurately determination of the changing time span between "not-explosive" and "explosive" to provide any necessary "early warning" messages.

Such research efforts not only can affect a well and accurate understanding of a mine's atmosphere, but also are important for the rescue workers' lives safety.

\section{Coward Explosibilty Diagram}

The Coward explosive triangle diagram which was published by Coward and Jones in 1952 has been considered as a fast and easy way to determine the explosibility of the 
gas-mixture. Currently, as the most popular method, it is widely used in the U.S. mining industry (McPherson, 1993; Coward and Jones, 1952). Basically speaking, the explosive triangle is defined by three characteristics points which are commonly generated by applying the Le Chaterlier's Principles. The diagram is divided into four different zone stated as the impossible mixture zone, the explosive zone, the not-explosive zone (but may become explosive if more combustibles or air are added) and another non- explosive zone. Figure 1 shows the Carbon Monoxide (CO) explosive triangle. Once a gas-mixture sampling from an atmosphere is analyzed and the state point is plotted on the diagram, the explosibility could be determined immediately.

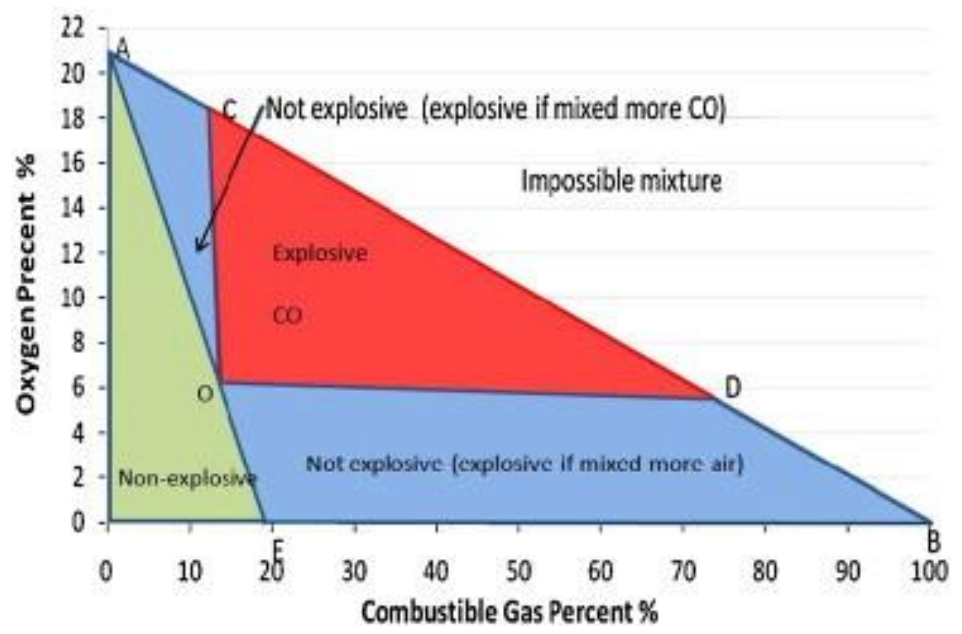

Figure $1 \mathrm{CO}$ explosive triangle (Cheng and Yang, 2011)

The Coward diagram can clearly identify the explosive status of gas-mixture and track its explosibility trend as the compositions of the gas-mixture change. However, it could not provide the information about the safety margin. In other words, this diagram is lack of capability to make an explosion risk assessment for the future time and people cannot truly understand the safety margin of a mine's atmosphere. Fortunately, the 
concept of explosibility safety factor (SF) has been proposed as one of preliminary solutions to address such problem (Cheng et al., 2013).

\section{State-of-art engineering needs for firefighting works}

Due to the coal spontaneous combustion problems, sealing a mined-out area in underground mines is very common to avoid any fire or explosion risks. Technical speaking, a sealed atmosphere in an underground coal mine is simply a volume governed by boundary conditions (Zipf and Mohamed, 2010), which can be understood by the following two aspects:

a) Methane has an explosive range between $5 \%$ and $15 \%$ and the concentration of $9.5 \%$ is the most dangerous scenario due to complete combustion of the air-methane mixture, which means that a newly sealed atmosphere must firstly become explosive in a short time and then turn into non-explosive in a long time due to the continuous methane emission in sealed area that could build the methane concentration up.

b) Using the inert gases to extinguish potential coal fires in mine gobs or control explosions is very common in the coal mines. Generally, the inert gas, $N_{2}$, is usually used to into the mine sealed area to maintain or create a non-explosive atmosphere. However, with methane emission from surrounding strata and $\mathrm{N}_{2}$ injection from outside simultaneously, the composition of sealed mine atmosphere could be greatly changed and, therefore, the explosibility should be carefully watched and analyzed. 
Hence, the trend prediction for the atmosphere composition in a sealed mine area is a complicated problem, which brings difficulties when making any ventilation management for a sealed mine atmosphere.

However, for engineering needs, the following two questions are often asked and also required to be answered for mine operators or mine rescue managers.

- Once an underground mined-out area is normally sealed, the methane concentration could build up due to the methane emission from strata. Hence, how long the duration time could last until the sealed atmosphere passes the "explosive range"?

- For a non-explosive atmosphere, how to determine that if the mine atmosphere is close to "explosive" zone or not under various combination of boundary conditions? In other words, is the "risk" enhanced or mitigated?

These are very important questions because it is so critical for either performing a successful mine fire extinguishing or allowing rescue workers to go underground doing operations.

\section{Explosion Risk Assessment Using Quantitative Analysis}

For the simplicity reason, three following categories of gases make up the gasexchanges in a sealed volume of coal mines. They are the methane gas flow, the inert gas $\left(\mathrm{N}_{2}\right)$ flow and the fresh air flow. Figure 2 shows a sealed volume and the mass exchanges between the volume and its surroundings. 


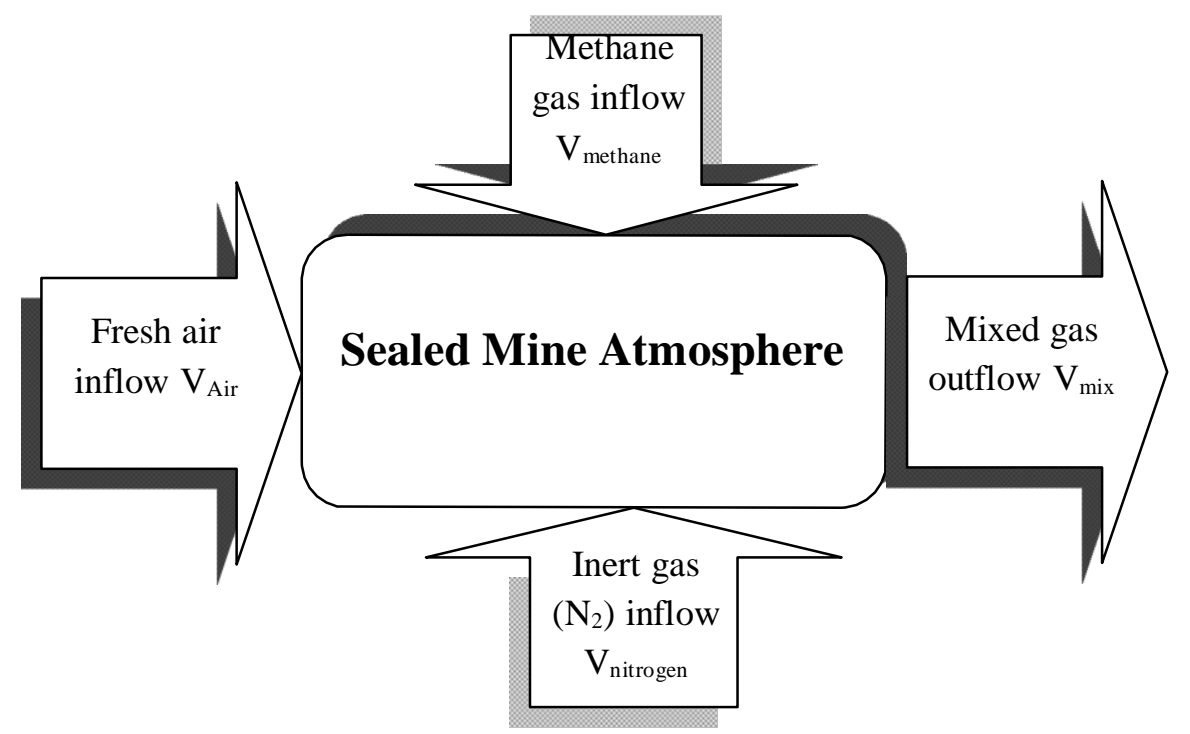

Figure 2 Composition changes in a seal mine atmosphere

Precisely, they all can be well expressed in the Coward explosibility diagram. Figure 3 shows that directions of a state point can be shifted by the addition of more combustible gas, more air or more inert gas (Holding, 1992). When the combustible gas is added to or subtracted from a sealed volume while a constant ratio between air and inert gas is maintained, the point representing the sealed atmosphere will move along a line joining the current state point to the $100 \%$ combustible point. If, instead of adding or subtracting combustible gas, air is added to the sealed atmosphere while a constant ratio between combustible gas and inert gas is maintained, the point will move from the current state point to the normal fresh air point. Similarly, if more inert gas is added, the point will move toward the origin of diagram. 


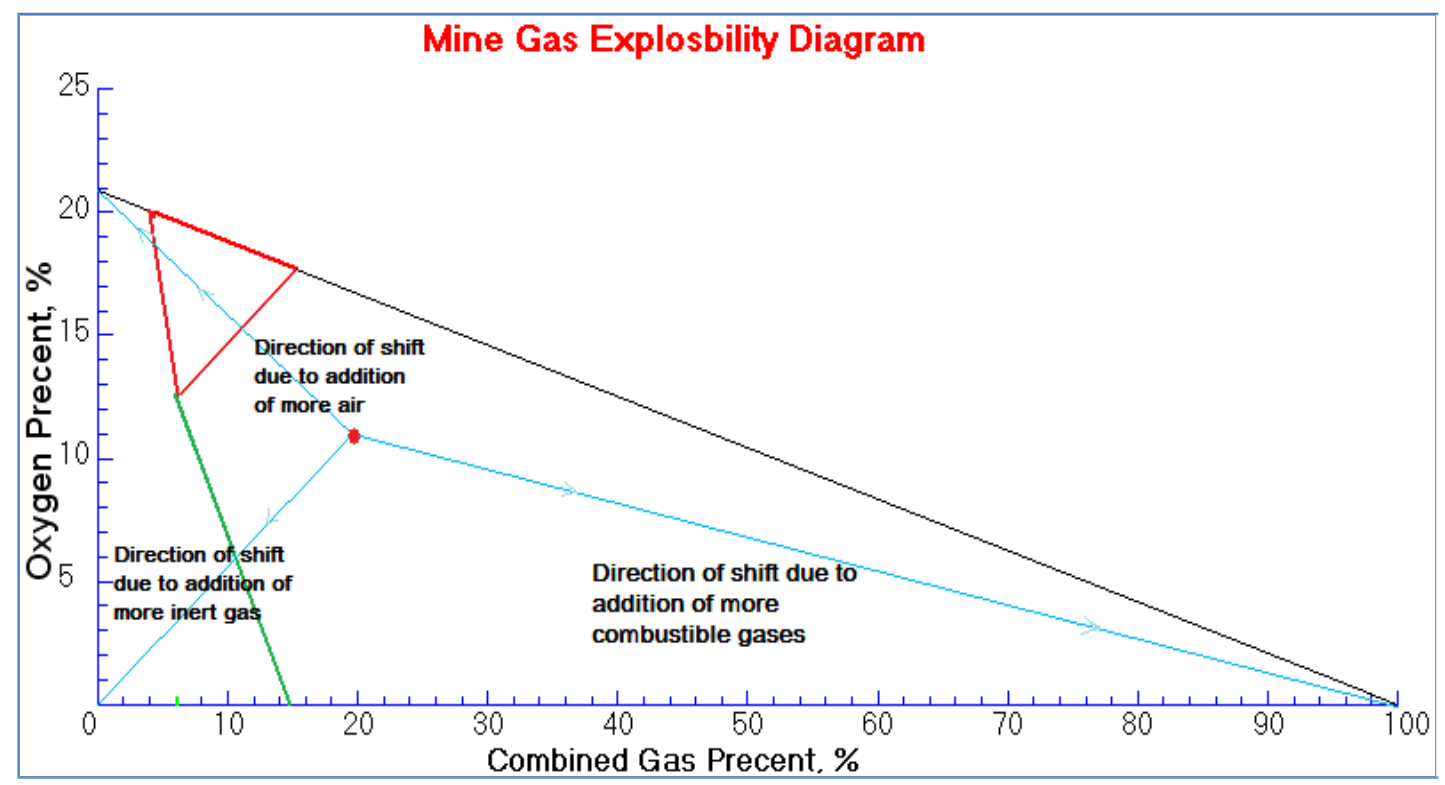

Figure 3 Illustration of Coward diagram characterizes

In this paper, in considering the point moving direction laws, zones in the diagram can be redefined as follows (as Figure 4 ):

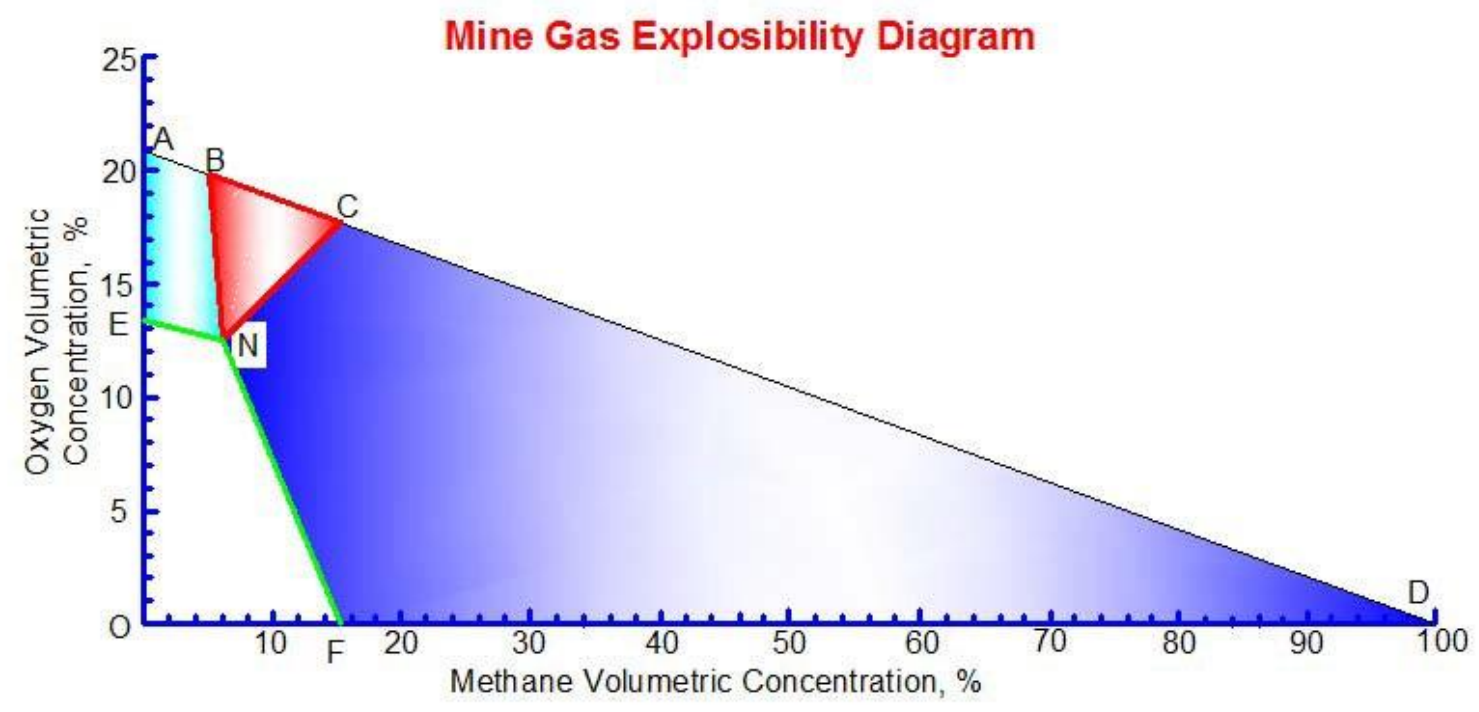

Figure 4 Zones division in explosibility diagram

- Zone BNC. It is the zone with potential of explosion, also called the 
explosibility triangle. The mine gas state point within this zone indicates that the mine atmosphere is explosive. Under this circumstances, mine operators intends to inject inert gas to phlegmatize the atmosphere fast (moving the state point out of the triangle)

- Zone CDFN. It is a not-explosive zone, but the status point in this zone has a special feature. By analyzing its potential moving direction, it can be found that the atmosphere may become "explosive" or maintain "not-explosive" depending on flowrates of methane and fresh air mixed in a mine atmosphere.

- Zone ABNE. It is also a not-explosive zone and also like the zone CDFN mentioned above. The status of atmosphere may become "explosive" once the methane inflow rate is large enough.

- Zone ENFO. It is the non-explosive zone, and can be considered as the "true" absolute safety zone. Whatever any gases (Methane gas, inert gas or fresh air) is added, its moving direction will not intersect the explosive triangle.

\section{Estimating "critical" ratios of various gas volumetric inflow rates to iudge}

\section{explosion risk}

Once a mine gas sample is obtained, the status point can be plotted on the explosibility diagram, the point's moving direction are highly dependent on the flowrates of methane, fresh air and inert gas. In other words, the gas point would move along the resultant of such flowrates. At the same time, it is also clear to see that the "resultant direction" of gas point could move toward or away from the explosive triangle. There 
must be a "critical" ratio of different gases injected into the mine atmosphere. Hence, this ratio can be considered as an indicator to assess the explosion risk of a mine atmosphere. In this section, the "critical" ratio will be discussed for each zones mentioned above.

- Zone CDFN: Figure 5 shows a gas sample located within zone CDFN. It could be seen that the gas point moving direction is totally dependent on the inflowrates of methane and fresh air and moves along the "resultant direction". If more fresh air is added, the gas point could move into the explosive triangle; conversely, more methane could force the gas point away from the triangle. Hence, there must be a "critical" situation that gas sample could move to the boundary of explosive triangle as shown in point " $\mathrm{C}$ " in this figure. Therefore, the "critical" ratio in this zone is the fresh air flow rate to methane flow rate. Once a ratio with larger than the "critical" one indicates the gas point moving toward the triangle and control measures for such mine atmosphere losing effects. The

"critical" ratio can be mathematically expressed as:

$$
\begin{gathered}
\left\{\begin{array}{c}
\cos (\angle C P D)=\frac{C P^{2}+P D^{2}-C D^{2}}{2 \cdot C P \cdot P D C P^{2}+} \\
\cos (\angle C P A)=\frac{P A^{2}-A C^{2}}{2 \cdot C P \cdot P A}
\end{array}\right. \\
\frac{V_{A i r}}{\operatorname{Sin}(\angle C P D)}=\frac{V_{C H 4}}{\operatorname{Sin}(\angle C P A)}
\end{gathered}
$$

Hence, the ratio of $\frac{V_{A i r}}{V_{C H 4}}$ could be derived out by using above system of equations. Once more air added or less methane reduced, the atmosphere has the 
potential risk to become an explosive one since the gas point move toward to the explosive triangle.

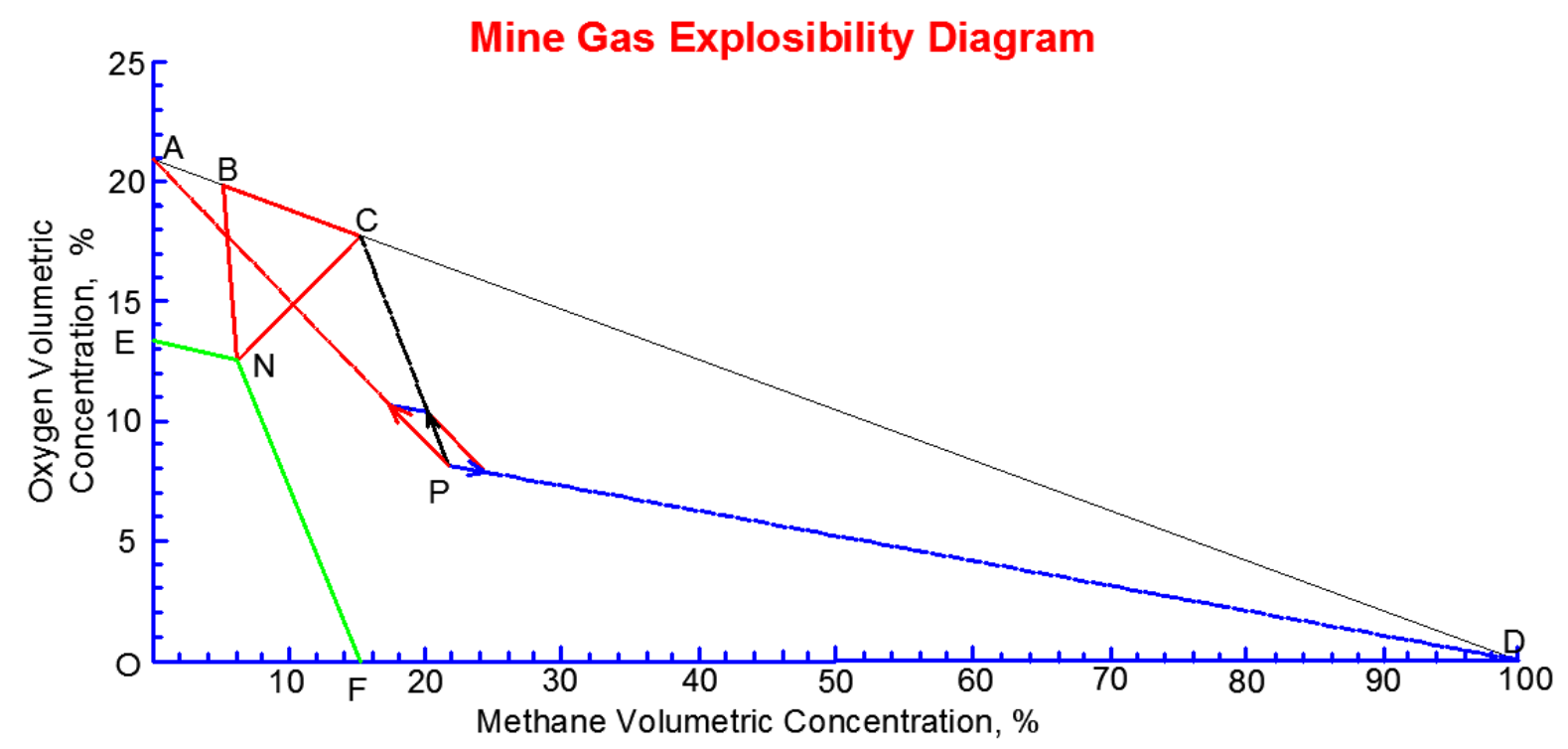

Figure 5 "critical" situation that a gas point moving to the boundary of explosive triangle

- Zone ABNE. Figure 6 shows a gas sample located within zone ABNE. The gas point moving direction is also totally dependent on the inflowrates of methane and fresh air and moves along the "resultant direction". If more methane is added, the gas point could move into the explosive triangle; conversely, more fresh air could force the gas point moving away from the triangle. Hence, the "critical" situation is that gas sample could move to the boundary of explosive triangle as shown point " $\mathrm{B}$ " in this figure. Therefore, the "critical" ratio in this zone is the methane flow rate to the fresh air flow rate. Once a ration with larger than 
the "critical" one indicating the gas point moving toward the triangle. The "critical" ratio can be mathematically expressed as:

$$
\left\{\begin{array}{l}
\left\{\begin{array}{l}
\cos (\angle B P D)=\frac{B P^{2}+P D^{2}-B D^{2}}{2 \cdot B P \cdot P D A P^{2}+} \\
\cos (\angle A P B)=\frac{P B^{2}-A B^{2}}{2 \cdot A P \cdot P B}
\end{array}\right. \\
\frac{V_{A i r}}{\operatorname{Sin}(\angle B P D)}=\frac{V_{C H 4}}{\operatorname{Sin}(\angle A P B)}
\end{array}\right.
$$

Hence, the ratio of $\frac{V_{C H} 4}{V_{A i r}}$ could be derived out by using above system of equations. Once more methane is added or less-air is reduced, the atmosphere has the potential risk to become an explosive one ${ }_{2}$ since the gas point move toward to the explosive triangle.

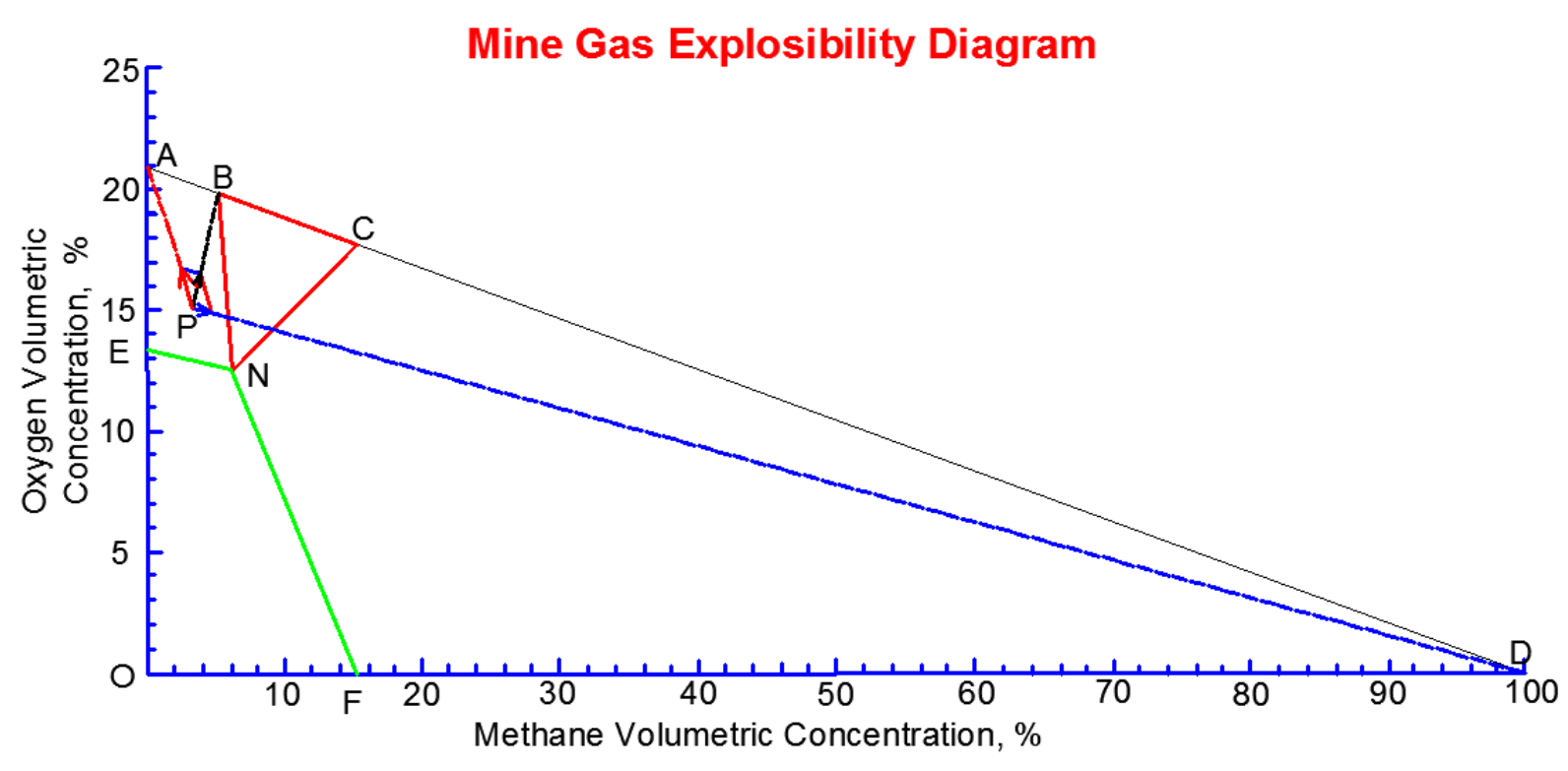

Figure 6 "Critical" situation that a gas point moving to the boundary of explosive triangle 


\section{Estimating time needed that a not-explosive atmosphere turning into explosive}

\section{zone}

The "resultant direction" of gas point shows moving behaviours of mine atmosphere in the explosibility diagram. If a further study is made, by extending the "moving direction" line, the intersection point of the mine atmosphere to the explosive triangle could be obtained. This may hint us that the compositions of the mine atmosphere when it becomes "explosive" could be known. Hence, based on the flowrates of methane or fresh air, it is possible to estimate the time needed for a not- explosive atmosphere to turn into an explosive one.

- Zone CDFN or zone ABNE. Figure 7 (a) and (b) show a gas sample located within the explosive zone CDFN or ABNE. The following procedure could be used to estimate the time:

1) Determine the "gas point's moving resultant direction": Since the gas point moving along the "resultant direction" which is dependent on the inflowrates of methane and fresh air, therefore, it could firstly project the gas point moving directions when only considers the effect of methane and fresh air, respectively. Then, the "resultant direction" could be determined. Let's suppose the coordinate of "P" is $(C, O)$ which indicates the methane concentration is " $\mathrm{C}$ " and the oxygen is "O". Eqs (3) and (4) give methane concentration " $\mathrm{C}_{A}$ " and the oxygen concentration " $\mathrm{C}_{B}$ " that once a methane or fresh air is added in a unit time.

$$
C_{A}=\frac{V_{\text {Methane }} \cdot t+V_{\text {Total }} \cdot C}{V_{\text {Methane }} \cdot t+V_{\text {Total }}}
$$




$$
C_{B}=\frac{0.21 * V_{\text {air }} \cdot t+V_{\text {Total }} \cdot O}{0.21 * V \cdot t+V}
$$

Note that, when doing calculation, the unit time (t) used in equations could be a random number, once " $\mathrm{C}_{A}$ " and " $\mathrm{C}_{B}$ " are known, the point " $\mathrm{P}_{A}$ " and " $\mathrm{P}_{\mathrm{B}}$ " could be plotted and the "gas point's moving resultant direction" can be shown.

2) Determine the intersection point: By extending the "moving direction" line, the intersection point of the mine atmosphere to the explosive triangle could be obtained. Hence, the coordinate of "P explosive" ( $\left.C_{\text {explosive, }} \mathrm{O}_{\text {explosive }}\right)$ could be read.

3) Estimate the time: the above derivation method can be re-applied again. The following equation can be given:

For Zone ABNE

$$
C_{\text {Explosive }}=\frac{V_{\text {Methane }} \cdot t_{\text {need }}+V_{\text {Total }} \cdot C}{V_{\text {Methane }} \cdot t_{\text {need }}+V_{\text {Total }}}
$$

Hence,

$$
t_{\text {need }}=\frac{V_{\text {Total }} \cdot C_{\text {Explosive }}-V_{\text {Total }} \cdot C}{V_{\text {Methane }}-V_{\text {Methane }} \cdot C_{\text {Explosive }}}
$$

For Zone CDFN

$$
O_{\text {Explosive }}=\frac{0.21 * V_{\text {Air }} \cdot t_{\text {need }}+V_{\text {Total }} \cdot O}{0.21 * V_{\text {Air }} \cdot t_{\text {need }}+V_{\text {Total }}}
$$

Hence,

$$
t \quad 14 \quad V_{\text {Total }} \cdot O_{\text {Explosive }}-V_{\text {Total }} \cdot O
$$


need $\quad 0.21 * V \quad-0.21 * V \quad . O$

Air Air Explosive 


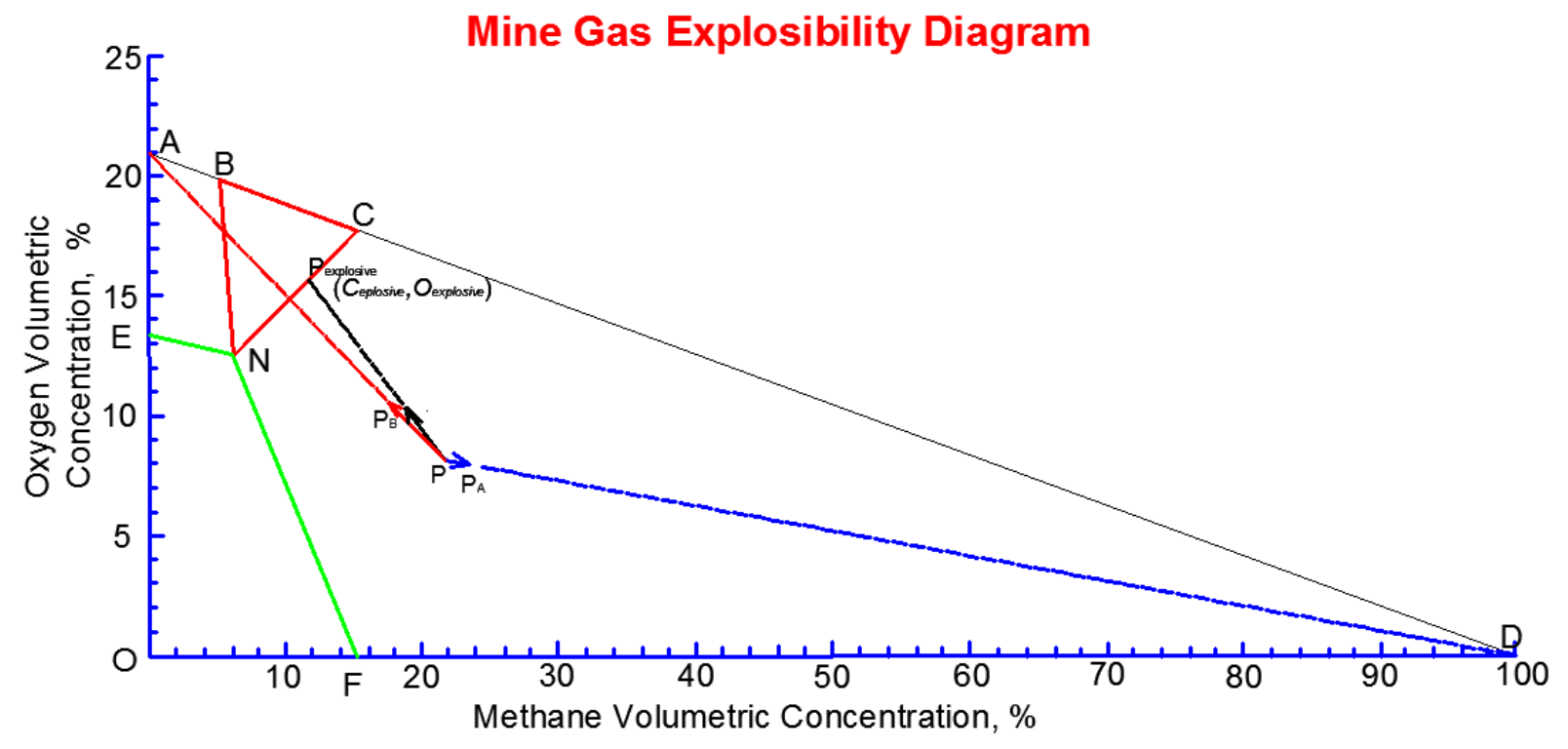

(a) gas point in zone CDFN

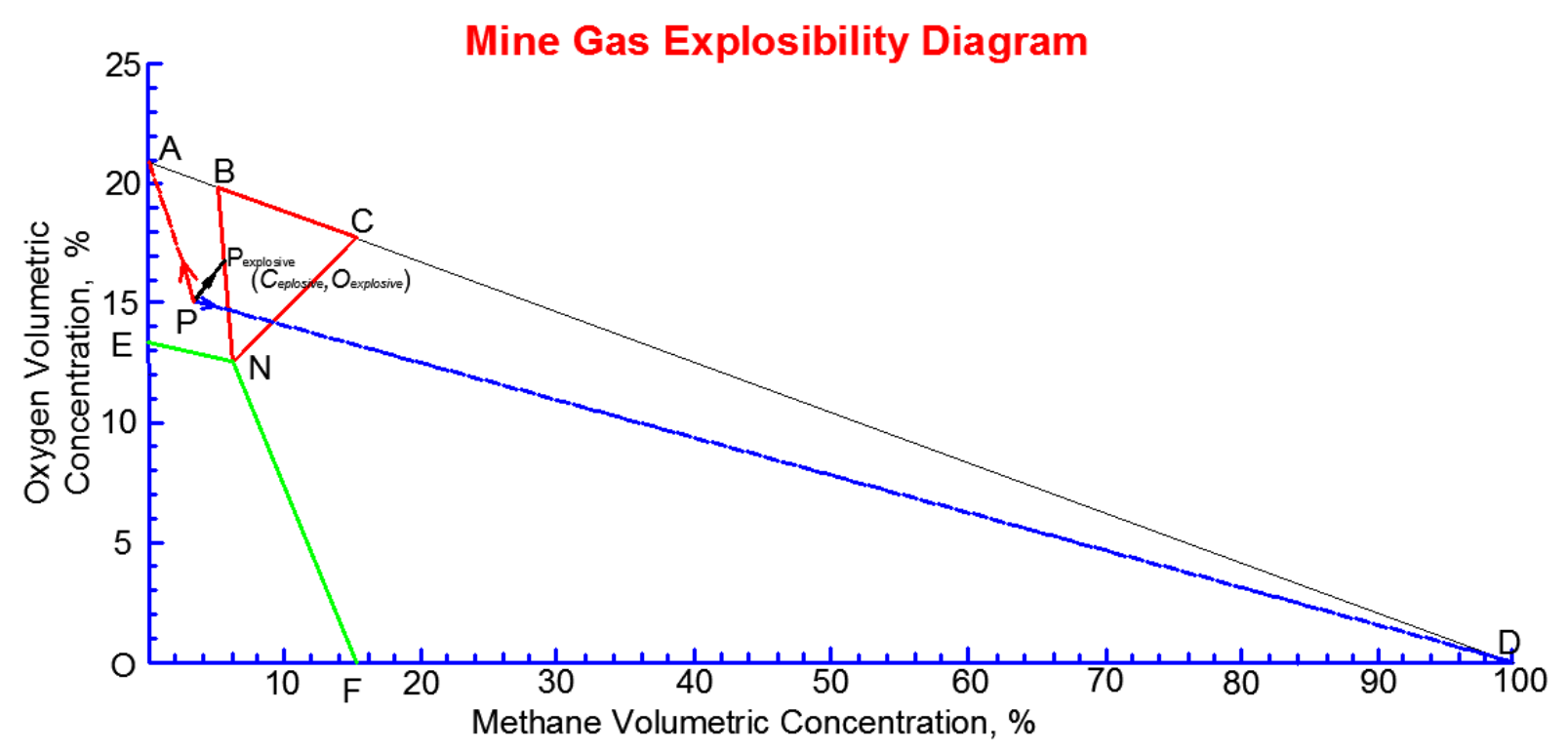

(b) gas point in zone ABEN

Figure 7 gas points moving to the boundary of explosive triangle

\section{Explosion Risk Mitigation Estimations for an explosive atmosphere}

Time needed that an explosive atmosphere moving out of explosive zone 
If a mine gas point indicating an explosive mine atmosphere located within the explosive triangle, mine operators are more interested in is that how long time is needed to achieve the state of self-inertisation for such atmosphere. Figure 8 shows a gas point located in the triangle. For coal mines, mine operators often injects the inert gas into the atmosphere to reduce the explosion risk. In addition, methane emitted from underground strata would also change the atmospheric compositions. Hence, as figure 8 shown, the "resultant direction" of gas point could move toward the boundary of explosive triangle. The estimation time should also be calculated using the method as the previous section, the coordinate of "Pexplosive" ( $\left.\mathrm{C}_{\text {explosive }}, \mathrm{O}_{\text {explosive }}\right)$ referring to Figure 8 ,

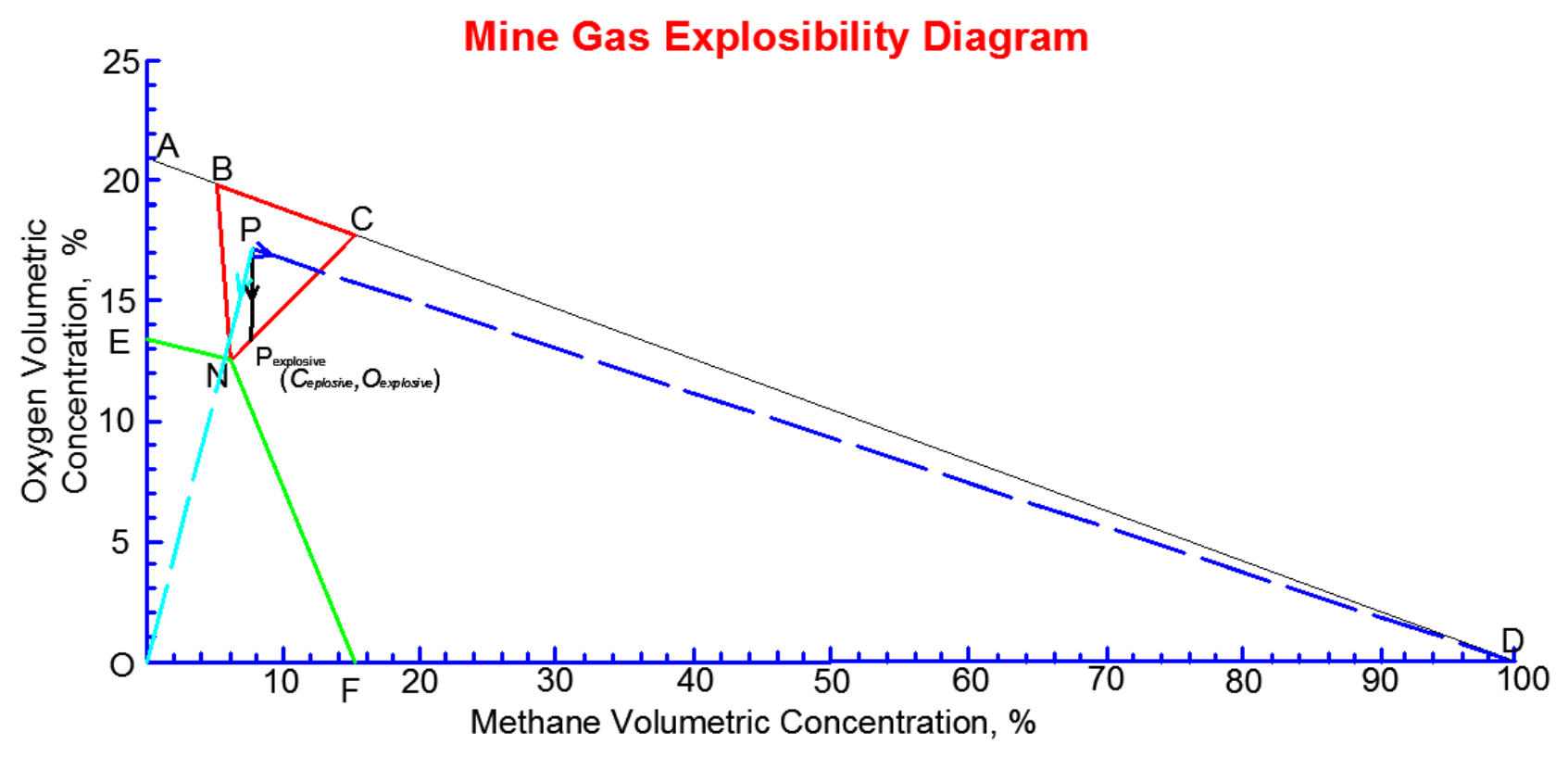

Figure 8 Gas point moving out of explosive triangle

For Zone BNC

$$
N_{\text {Explosive }}=\frac{V_{\text {Nitrogen }} \cdot t_{\text {need }}+V_{\text {Total }} \cdot N}{V_{\text {Nitrogen }} \cdot t_{\text {need }}+V_{\text {Total }}}
$$

Hence, 


$$
t_{\text {need }}=\frac{V_{\text {Total }} \cdot N_{\text {Explosive }}-V_{\text {Total }} \cdot N}{V_{\text {Nitrogen }}-V_{\text {Nitrogen }} \cdot N_{\text {Explosive }}}
$$

\section{Maintain the best ratio of various gas inflow rates to mitigate explosion risk}

Once a mine gas point indicating an explosive mine atmosphere located within the explosive triangle, forcing the explosive mine atmosphere to become a non-explosive one to reduce the explosive risk is important for mine operators, by analyzing the explosive diagram, it can be found that the gas point could move follow a line which is perpendicular to the boundary of explosive triangle. In that case, the "Critical" time is the least one and show the maximum possibility to reduce the explosion risk. Generally, the inflow rate of methane cannot artificially be controlled since it is dependent on the minesite geological conditions. Hence, the inflow rate of nitrogen must be carefully maintained to form the "efficiency" moving direction.

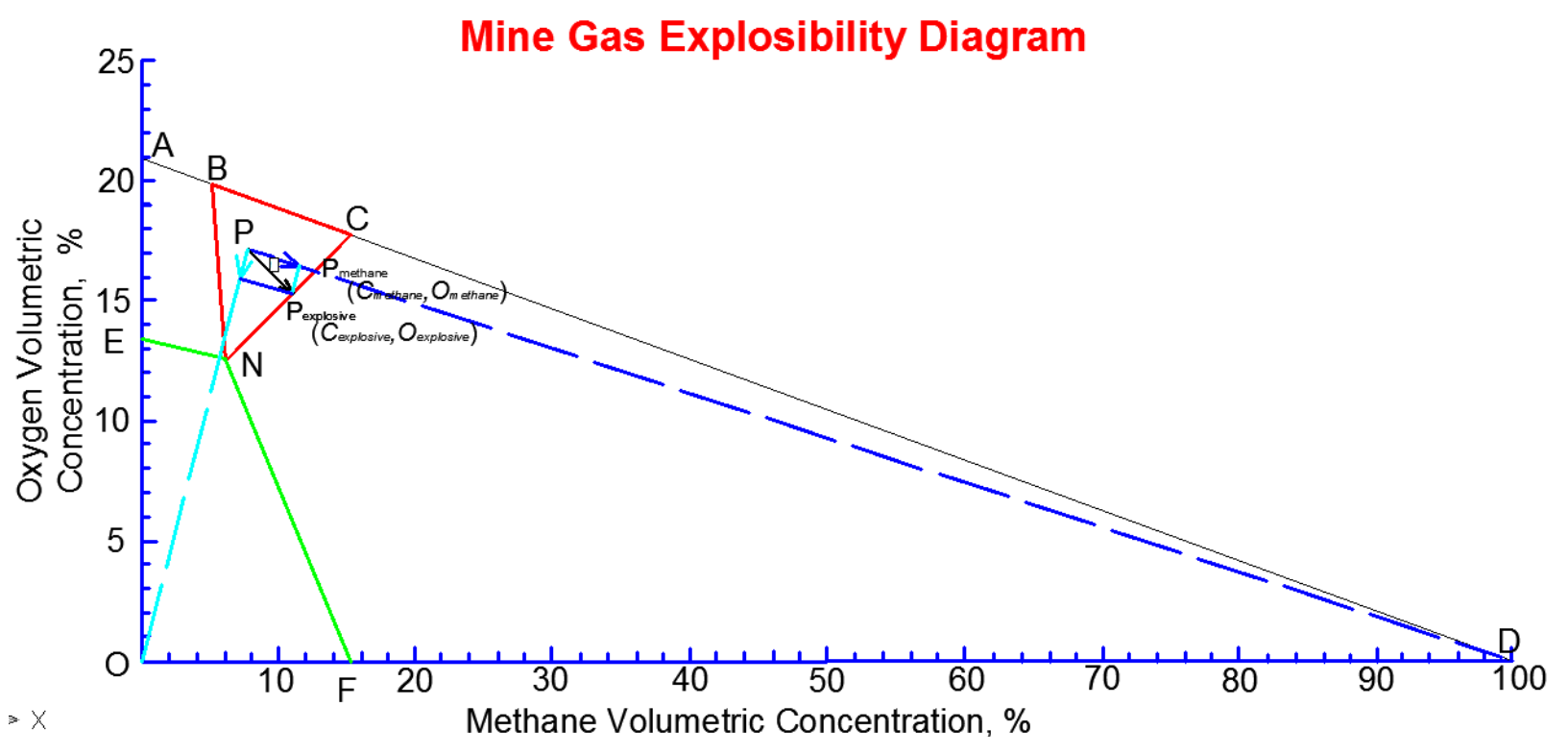

Figure 9 Gas point moving out of explosive triangle in a short way 
The above derivation method can be also re-applied again. But the procedure should be modified.

1) Staring from the gas point to plot a line to determine the coordinate of " $P_{\text {explosive" }}$ ( $\mathrm{C}_{\text {explosive, }}$ Oexplosive) in the explosive boundary. The "resultant direction" could be determined.

2) Extending the line of adding more methane to obtain the a intersection point with the explosive triangle, the coordinate is expressed as " $\mathrm{P}_{\text {methane }} \quad\left(\mathrm{C}_{\text {methane }}\right.$, Omethane).

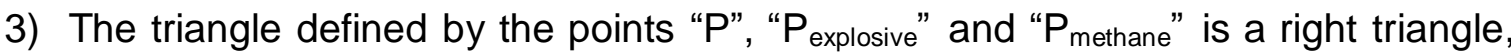
the best ratio of the inflow rate of nitrogen to the inflow rate of methane could be expressed as the tangent of " $\theta$ " shown in the figure 9 , and could be mathematically written as:

$$
\tan (\theta)=\frac{V_{\text {Nitrogen }}}{V_{\text {Methane }}}=\frac{P_{\text {methane }} P_{\text {explosive }}}{P P_{\text {exp losive }}}
$$

Once this ratio is maintained, it can make sure that the gas point could move out of the explosive triangle in a manner of using the shortest time.

\section{Case Demonstration}

Case 1: A gas sample taken from a sealed mine volume yields the mixture composition as follows: $\mathrm{CH}_{4}: 22 \% ; \mathrm{N}_{2}: 70 \% ; \mathrm{O}_{2}: 8.00 \%$. The total underground sealed volume is $100,000 \mathrm{~m}^{3}$ and the methane volumetric inflow rate in the sealed area is $0.4 \mathrm{~m}^{3} / \mathrm{s}$. Determine 1) more fresh air could induce the gas point moving into the explosive triangle, what is the maximum of the inflow rate of fresh air should be kept below in order to 
reduce the explosion risk? (As shown in figure 5) 2) if the inflow rate of fresh air is $4 \mathrm{~m}^{3} / \mathrm{s}$, how long time will the mine atmosphere need to become "explosive"? (As shown in figure $7(a))$

Solutions: 1) using the Eq. (1), the maximum "critical" ratio of the fresh air inflow rate to methane in flow rate $\frac{V_{A i r}}{V_{C H}}=1.83$, which means if the fresh air inflow rate is over $0.73 \mathrm{~m}^{3} / \mathrm{s}$, the gas point would move forward the explosive triangle; 2) using Eqs(3) and (4) to determine the gas point's moving resultant direction. Thus, the coordinate of "Pexplosive" $(12,16)$ could be read. Then, applying the Eq(6), this "not-explosive" mine atmosphere could become-explosive in about $11,338 \mathrm{~s}$ (3.15h) under the condition of $4 \mathrm{~m}^{3} / \mathrm{s}$ inflow rate of fresh air.

Case 2: A gas sample taken from a sealed mine volume yields the mixture composition as follows: $\mathrm{CH}_{4}: 2 \% ; \mathrm{N}_{2}: 83 \% ; \mathrm{O}_{2}: 15.00 \%$. The total underground sealed volume is $100,000 \mathrm{~m}^{3}$ and the methane volumetric inflow rate in the sealed area is $0.4 \mathrm{~m}^{3} / \mathrm{s}$. Determine 1) more methane could induce the gas point moving into the explosive triangle, what is the minimum of the inflow rate of fresh air should be kept below in order to reduce the explosion risk? (As shown in figure 6) 2) if the inflow rate of fresh air is $1 \mathrm{~m}^{3} / \mathrm{s}$, how long time will the mine atmosphere need to become "explosive"? (As shown in figure 7(b))

Solutions: 1) using the Eq. (2), the minimum "critical" ratio of the fresh air inflow rate to methane in flow rate $\frac{V_{C H 4}}{V_{A i r}}=0.82$, which means if the fresh air inflow rate is less than $2.05 \mathrm{~m}^{3} / \mathrm{s}$, the gas point would move forward the explosive triangle; 2) using Eqs(3) and (4) to determine the gas point's moving resultant direction. Thus, the coordinate of 
"Pexplosive" $(5.6,16.8)$ could be read. Then, applying the $\mathrm{Eq}(8)$, this "not-explosive" mine atmosphere could become-explosive in about 9,534s (2.65h) under the condition of 1 $\mathrm{m}^{3} / \mathrm{s}$ inflow rate of fresh air.

Case 3: A gas sample taken from a sealed mine volume yields the mixture composition as follows: $\mathrm{CH}_{4}: 8 \% ; \mathrm{N}_{2}: 75 \% ; \mathrm{O}_{2}: 17.00 \%$. The total underground sealed volume is $100,000 \mathrm{~m}^{3}$ and the methane volumetric inflow rate in the sealed area is $0.4 \mathrm{~m}^{3} / \mathrm{s} .1$ ) if the inflow rate of nitrogen is $40 \mathrm{~m}^{3} / \mathrm{s}$, how long time will the mine atmosphere need to become "not-explosive"? (As shown in figure 8) 2) estimate the best ratio of the inflow rate of nitrogen to the inflow rate of methane which can move the gas point moving out of the explosive triangle in a shortest time.

Solutions: 1) using Eqs(3) and (4) to determine the gas point's moving resultant direction. Thus, the coordinate of "Pexplosive" $(7,13)$ could be read. Then, applying the $E q(10)$, this "explosive" mine atmosphere could become not-explosive in about $625 \mathrm{~s}$ under the condition of $40 \mathrm{~m}^{3} / \mathrm{s}$ inflow rate of nitrogen.2) using the Eq. (11), the $\frac{V_{\text {Nitrogen }}}{V_{\text {Methane }}}$ is calculated as 1.67 , which means the gas point could move out of the explosive triangle in a shortest time.

\section{Conclusions}

Precise understanding (not only explosibility, but also changing trend) the underground mine atmosphere is very critical for miners' safety. In this paper, a series of mathematical analyzing models have been proposed to deeply understanding the behavior of a mine atmosphere under various combination of boundary conditions, which 
include to judge the trend of explosion risk or to estimate the state changing time from "not-explosive" to "explosive". Moreover, for an explosive atmosphere, it is also pointed out the related risk mitigation estimations. The most important value of this research working is to achieve the objective of quantitative analyzing the explosion risk while it only can make qualitative judgments based on the explosibility diagrams in the past. Thus, it has a better applicability and could be used as scientific-sound safety guidelines in mine field management, especially for works of controlling an explosive atmosphere. Such research efforts can well help mining engineers improve their understanding of mine sealed volume.

\section{Acknowledgments}

This work is financially supported by grants from the "Endeavour Research Fellowship" by the Australian Government, Fundamental Research Funds for Central Universities (Grant No. 2013QNA01), the National Science Foundation of China (Grant No.51304203), the Natural Science Foundation of Jiangsu Province of China for Youths (Grant No. BK20130191) and Specialized Research Fund for the Doctoral Program of Higher Education (Grant No. 20130095120001); the Program for Changjiang Scholars and Innovative Research Team in University (IRT13098) and Priority Academic Program Development of Jiangsu Higher Education Institutions; the authors are grateful for these supports.

\section{References}

Britton, L.G., 2002. Two hundred years of flammable limits. Process Safety Progress, 
21(1): 1-11.

Cheng, J. and Yang, S., 2011. Improved Coward explosive triangle for determining explosibility of mixture gas. Process Safety and Environmental Protection, 89(2): 89-94.

Cheng, J., Luo, Y. and Zhou, F., 2013. Explosibility safety factor: an approach to assess mine gas explosion risk. Fire Technology, 51(2): 309-323.

Cheng, J., Wang, C. and Zhang, S., 2012. Methods to determine the mine gas explosibility-An overview. Journal of Loss Prevention in the Process Industries, 25(3): 425-435.

Coward, H.F. and Jones, G.W., 1952. Limits of flammability of gases and vapors, DTIC Document.

Holding, W., 1992. A re-look at explosibility diagrams. In: R. Hemp (R. Hemp). Proceedings of the 5th International Mine Ventilation Congress, Johannesburg,Republic of South Africa, pp. 171-181.

Huang, S., 2010. China Coal Outlook 2010. China Coal Industry Publishing House, Beijing, China.

Ishizuka, S., 1991. Determination of flammability limits using a tubular flame geometry. Journal of Loss Prevention in the Process Industries, 4(3): 185-193.

Jacobs, M. and Porter, I., 1998. Rapid generation of control charts for analysis of complex gas mixes in crisis situations. Proceedings of Coal: 641-648.

Kukuczka, M., 1982. A new method for determining explosibility of complex gas mixtures. Mechanizacja I Automatuzacja Gornictwa, 164(11): 36-39.

Ma, T., 2011. A thermal theory for estimating the flammability limits of a mixture. Fire 
Safety Journal, 46(8): 558-567.

Ma, T., 2013. A thermal theory for flammability diagrams guiding purge and inertion of a flammable mixture. Process Safety Progress, 32(1): 42-48.

Ma, T. and Larrañaga, M., 2015. Theoretical Flammability Diagram for Analyzing Mine Gases. Fire Technology, 51(2): 271-286.

Mashuga, C.V. and Crowl, D.A., 2000. Derivation of Le Chatelier's mixing rule for flammable limits. Process safety progress, 19(2): 112-117.

McPherson, M.J., 1993. Subsurface ventilation and environmental engineering. Springer Science \& Business Media.

Ray, S.K., Singh, R.P., Sahay, N. and Varma, N.K., 2004. Assessing the status of sealed fire in underground coal mines. Journal of scientific \& industrial research, 63(7): $579-591$

Timko, R.J. and Derick, R.L., 2006. Methods to determine the status of mine atmospheresan overview. Journal of the Mine Ventilation Society of South Africa (SAUS): 1-9.

Zipf, R.K. and Mohamed, K.M., 2010. Composition change model for sealed atmosphere in coal mines, Proc. 13th United States/North American Mine Ventilation Symposium, Ed. S. Hardcastle and D. McKinnon, Laurentian University, Sudbury, pp. $493-500$ 